\title{
A Global Social Support System: What the International Community Could Learn From the United States' National Basketball Association's Scheme for Redistribution of New
} Talent

\author{
Gorik Ooms ${ }^{1,2}$, David Stuckler ${ }^{3,4}$, Sanjay Basu ${ }^{5}$, Martin McKee ${ }^{4^{*}}$
}

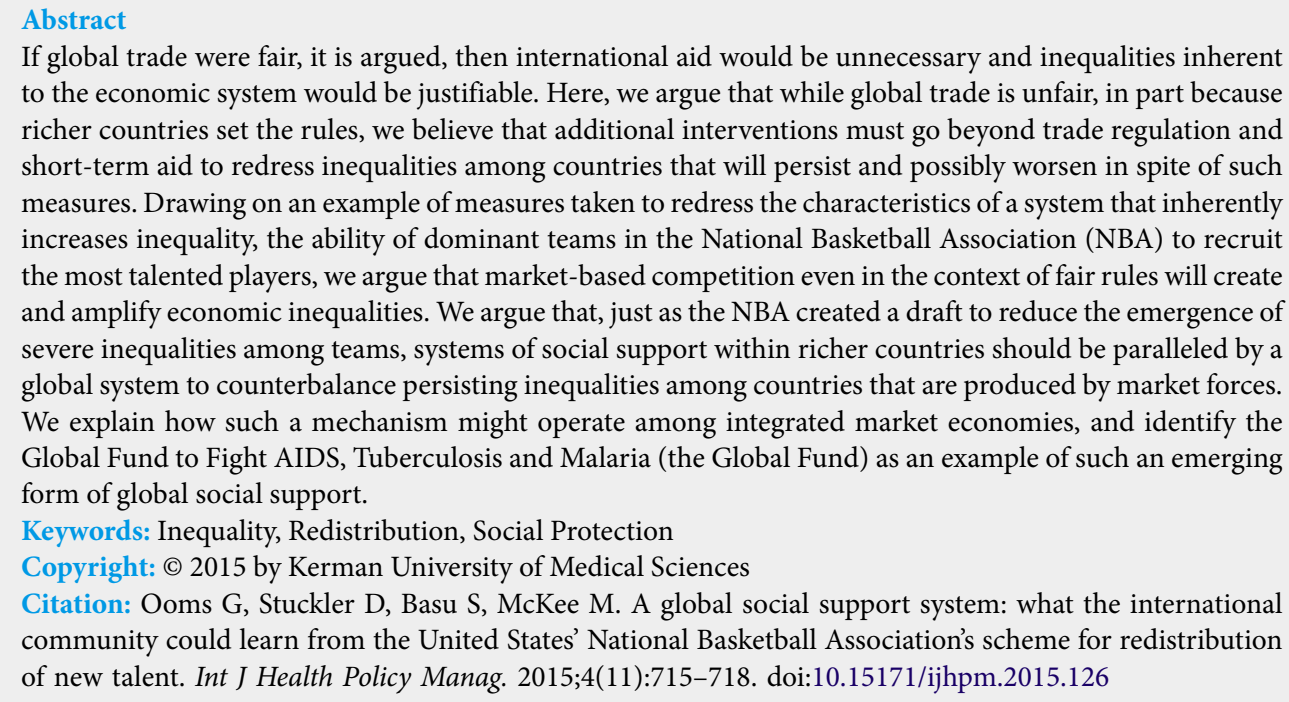

If global trade were fair, it is argued, then international aid would be unnecessary and inequalities inherent to the economic system would be justifiable. Here, we argue that while global trade is unfair, in part because richer countries set the rules, we believe that additional interventions must go beyond trade regulation and short-term aid to redress inequalities among countries that will persist and possibly worsen in spite of such measures. Drawing on an example of measures taken to redress the characteristics of a system that inherently increases inequality, the ability of dominant teams in the National Basketball Association (NBA) to recruit the most talented players, we argue that market-based competition even in the context of fair rules will create and amplify economic inequalities. We argue that, just as the NBA created a draft to reduce the emergence of severe inequalities among teams, systems of social support within richer countries should be paralleled by a global system to counterbalance persisting inequalities among countries that are produced by market forces. We explain how such a mechanism might operate among integrated market economies, and identify the Global Fund to Fight AIDS, Tuberculosis and Malaria (the Global Fund) as an example of such an emerging form of global social support.

Keywords: Inequality, Redistribution, Social Protection

Copyright: $\odot 2015$ by Kerman University of Medical Sciences

Citation: Ooms G, Stuckler D, Basu S, McKee M. A global social support system: what the international community could learn from the United States' National Basketball Association's scheme for redistribution of new talent. Int J Health Policy Manag. 2015;4(11):715-718. doi:10.15171/ijhpm.2015.126

Article History:

Received: 26 March 2015

Accepted: 8 July 2015

ePublished: 9 July 2015
Rules, Redistribution, and the National Basketball Association Draft

Professional sports teams that win have at least 2 advantages over losing teams in the subsequent season: $(a)$ better starting conditions (such as possession of the top players and coaches); and $(b)$ greater ability to maintain their lead, as they earn more money than poorer teams to recruit new players with higher salaries.

These advantages prevailed in the early years of US basketball as the best teams recruited the top regional and college basketball players every year. The result was a relatively rigid and unequal system, whereby the winners stayed on top and the losers fell behind. Games became predictable and less competitive as the dominant regional team would inevitably win, eroding the sporting ethos, and drawing fewer crowds. ${ }^{1}$ Even though the sport was suffering, the system was selfperpetuating: winners continued to recruit the best players, drawing on their money and prestige. In 1947, the then Basketball Association of America (now the NBA) introduced a draft to correct for these imbalances. Teams were given turns selecting amateur US basketball players, in reverse order of their win-loss record in the previous seasons. The draft gave the worst performing teams the first pick of new, talented college rookies. These rookie picks are highly valued, and can be traded to other teams for cash or even other players. The draft is essentially a system of redistribution. It counters the 'first' distribution of winners and losers from the competitive process that, on its own, would enable winning teams to maintain their lead in the next season by earning more money and support. By acting as a 'second' redistribution, the draft is intended to create a fairer playing field - and ultimately a more exciting game - than would arise in a situation of accumulating inequalities between teams. Redistributing players in this way is designed to prevent inequalities from becoming so extreme as to harm the overall well-being of the NBA as a sporting enterprise.

The redistributive characteristics should mitigate the continuing accumulation of inequalities arising from teams' advantages over each other and enhance the basketball league overall by increasing competitiveness, while neither creating a totalitarian system that forces players onto certain teams, nor eliminating the skills gap between teams by forcing total equity. Assessing the extent to which drafts such as this achieve their stated goals is complicated because of the other features of each system, including how it addresses the incentive to lose matches for future gain ${ }^{2}$ and what happens to those recruited in subsequent years. ${ }^{3}$ Evaluating the impact of the NBA draft is further complicated by the introduction of a 
series of changes, such as those that have incentives selection of less experienced players ${ }^{4}$ as well as the role of other influences on players' career trajectories, of which racial discrimination is the most studied. ${ }^{5}$ Nonetheless, it is the principle that is important as there are many other situations in which there are entrenched inequalities which stifle competition.

One such situation, of considerable contemporary relevance given discussions on the post-2015 development agenda, is the distribution of global income. As Milanovic has noted, although there is some evidence of progress in narrowing inequalities among countries, the gap remains wide. ${ }^{6} \mathrm{He}$ contrasts the situation whereby "[s] ociety tries to limit these inherited advantages by either taxing wealth or by making education, health etc. available to all, regardless of their income level" with the "global world," in which no such mechanisms exists. ${ }^{6}$ In this paper, we ask whether we can learn anything from the NBA draft about the scope for addressing these global inequalities?

The NBA's draft system has been cited by Rawls to illustrate what he called 'background institutions' required for justice: "background institutions must work to keep property and wealth evenly enough shared over time to preserve the fair value of the political liberties and fair equality of opportunity over generations." It has parallels with aspects of the economic system that combine market-based competition with redistributive social protection mechanisms within a country. Individuals and firms compete in the market place (playing field) but governments (NBA) then redistribute resources for mutual benefit. This redistribution does not involve picking players but rather takes the form of 'social spending, accounting for about $20 \%$ of national income of rich countries. ${ }^{8}$ This social spending creates opportunities for the most disadvantaged members of society to avoid harm resulting from poverty and to tide them over temporary misfortunes. Social support programmes include investments in job creation and retraining, theoretically enabling individuals and firms to develop talents and use them for their personal prosperity and - through taxation-to produce further social support systems for the prosperity of their compatriots.

In contrast, such redistributive measures are largely absent from the global economy, which envisages that progress will come about primarily from free trade, with explicit redistribution limited to time-dependent and, in the scheme of things, relatively small-scale aid. Free trade is viewed as benefitting everyone; it is considered in the interests of states to trade regardless of whether their trading partners are more or less advanced. ${ }^{9}$ This draws on Ricardo's theory of comparative advantage, which emphasises that each country should specialise in an area where it has a trade advantage over the other. In such circumstance, trade is assumed to make both countries better off, because they can maximise their strengths.

Yet there has never been fair competition in global trade. Analogous to the NBA before the draft, there were 2 important mechanisms of inequality. First, the rich countries had a head start. African and Asian countries were poorly prepared for independence by their experience of colonisation and exploitation. These countries had very little capital, few professionals and an extremely limited capacity to train future business leaders. Under the premise that their low labour costs would create a situation where capital and resources flowed toward them, they were soon required to abandon protectionism and compete with countries benefiting from centuries of knowledge and capital accumulation. Second, rich countries attract both capital and human resources from poor countries. Unlike the NBA, however, the global market has no draft mechanism to help poor countries attract talented 'players.' In fact, the opposite occurs through 'brain drain' of talent in poor countries to the rich (while those without recognised talents to offer are increasingly excluded from rich countries by ever more stringent barriers to migration). In combating such entrenched inequalities, the NBA draft is not a panacea. It is embedded in a much more complex system of cross-subsidies, such as rules for sharing gate and television revenue and a salary cap, whereby the total payroll of each team is limited (although there are numerous exceptions). ${ }^{10}$ For any global redistributive system to tackle longstanding challenges of brain drain and the disadvantages from decades of underdevelopment would also require additional crossnational transfers of resources, many of which will likely prove politically and economically challenging.

And there is a third mechanism of inequality: rich countries set the rules. Whereas the referees of the NBA can be presumed to be objective, as they are hired and paid by the league, at least 3 'referees' in the global market-the World Bank, the International Monetary Fund (IMF) and the World Trade Organisation (WTO) - have been designed by rich countries and have often acted in their interests. This allows rich countries to require poor countries to down-scale measures that protect their economies, and the health and welfare of their population, ${ }^{11}$ while rich countries can perpetuate subsidies that support their strategic interests and domestic electorates. ${ }^{12}$ This is only somewhat different to the historic enforcement of trading rules by military force, as in the 19th century Opium Wars between Great Britain and China. Now, political force may be more subtle, but is equally powerful, as in the pressure brought to bear by American governments seeking to block domestic anti-tobacco legislation in Southeast Asia in the 20th century. ${ }^{13}$ The level playing field envisaged in the rhetoric of the global financial institutions remains as illusory as ever.

In sum, our analysis suggests to us that, while the persistence of inequalities among countries can, at least in part, be blamed on unfair regulation of the global market (rich countries setting the rules), the lack of a redistributive mechanism at an international level is also a factor.

\section{Modest Beginnings of a Global Social Support System}

Unless the global trade system that creates massive inequalities can be countered, progress towards future sustainable development goals (SDGs) will be limited. While recognising that it cannot be a solution on its own, a system analogous to the NBA that could redistribute resources could contribute to this objective. But what might such a system look like?

We envision a fund for global social support to underpin the SDGs. This would, like the IMF, be a pool of funds available to member states. It differs, however, in that the winning countries in the international trade system would put in a portion of their winnings (a tax) each year, while the losing 
countries in the international trade system would have a sustained, domestic-welfare-like system of social support. Elsewhere we have shown that such a scheme could meet the $\$ 50$ per person target for low-income countries with a fund of between $\$ 169$ and $\$ 821$ billion per year, which is between $0.25 \%$ and $1.27 \%$ of per capita income from participating countries. ${ }^{14}$ This is more than high-income countries currently contribute to international development assistance, but this scheme is fundamentally different from conventional development assistance. Furthermore, as poorer countries grow, the gap, and thus the size of the fund, would narrow over time. For example, it would boost the ability of low-income countries to compete in world markets, thereby widening the pool of producers, while also alleviating many social problems which are ineffectively being addressed by current aid systems. An alternative scheme would require only $\$ 43$ billion per year, but leans closer to conventional 'donor-to-recipient' aid. ${ }^{15}$

Of course, some will argue that in the absence of a global government, a global social support system is impossible. Who would decide which countries should contribute how much, which countries should benefit and for how long, and what should the money be put towards? Would there be constraints on what the money might be spent on and would there be penalties for corruption? It would be premature to specify how such funds should be allocated and what strings might need to be attached to ensure it adds value for poor countries and poor people in those countries. The design would need to address known deficiencies in the existing aid system, including aid diversion (such as when aid is used for military spending) and displacement (such as a when aid simply replaces money that governments would have otherwise spent). We recognise that these details need to be agreed but we also note that such a system already exists, albeit on a relatively small scale. The international community has established systems that create global social support without a global government. As one precedent, some years ago the World Bank announced that its International Development Association (IDA) secured an unprecedented US $\$ 49.3$ billion funding package for the following 3 years. ${ }^{16}$ This was the result of the 16th IDA 'replenishment': over 5 decades, the IDA managed to gradually increase its resources, now contributed by 51 countries. The IDA has agreed criteria that classify its members into beneficiaries, contributors, or in between both (neither beneficiary nor contributor). This creates a mechanism by which global social support could be permanent, while countries change positions in the scheme. This is the essence of mutuality as winners and losers change places in the long run. However, the IDA is also limited and insufficient. It provides nearly all of its assistance as loans for time-bound projects; both elements indicate the intended temporality of the assistance. Moreover, it is well-known that the recipient countries have been mired in debt due to the loan-based nature of this aid, and that the temporality has produced serious problems for the development of permanent infrastructure for domestic social support systems like healthcare and education institutions.

Another precedent for international social support is the Global Fund to Fight AIDS, Tuberculosis and Malaria (the Global Fund). The Global Fund explicitly aims to provide sustained (for as long as countries need it) social support, as seen in its guidelines to applicants stating that " $\mathrm{t}]$ he applicant is not required to demonstrate financial self-sufficiency for the targeted interventions by the end of the proposal term." ${ }^{17}$ In an earlier paper, we argued that the Global Fund, if it were given a replenishment system like the IDA as, could serve as a foundation for a global social health protection fund. ${ }^{18}$ The Global Fund also offers some lessons on ways to address some of the challenges that a global social health protection fund would face, such as the involvement of civil society organisations to increase transparency and accountability. ${ }^{19}$

\section{Conclusions}

When considering a dilemma being discussed around the world-should efforts to accelerate the reduction in global inequalities mainly focus on fair regulation of the global market, as in "fair trade not aid," 20 or also aim to establish a global social support system between countries, as in 'fair trade and better aid' - we can learn from the history of rich countries. Market regulation-with governments imposing minimum wages, prohibiting child labour, and protecting the freedom to organise in unions-contributed significantly to reducing inequalities in years past. Market regulation went hand-in-hand with the creation of social support systems: the greater the market, the greater the need for support to ensure fair competition. ${ }^{21}$ Publicly financed education, healthcare and income replacement support decreased the vulnerability of wage-dependent workers, both allowing them to demand stronger market regulation and enabling them to play a part in the marketplace. ${ }^{22}$

A sustained system for international social support (a new type of global fund) is both needed and feasible. The Global Fund was not conceived as an institution for global social support, as it is directed almost exclusively to 3 diseases rather than broader issues of healthcare, education, housing and food; yet its ability to provide open-ended support probably stems from the realisation that AIDS treatment should not be interrupted (and that some countries would remain too poor to take over the financial burden of treatment). That could become the-perhaps accidental-legacy from the global fight against HIV to global social justice. ${ }^{23}$ Chronic problems of AIDS, malnutrition, and poverty all require permanent solutions.

Although we are still far away from a comprehensive global social support system, the Global Fund shows that such a fund is possible without a global government. What seems to be needed is, first, a common understanding that global social support is just as important for further reducing global inequalities as is fair regulation of the global market economy, and that social support systems have been essential in reducing inequalities and sustaining stable communities in rich countries. If even a simple sports competition-obeying to simple rules, applied by objective referees-requires permanent redistribution to maintain fairness and enhance competitiveness, how would market forces alone be able to reduce global inequalities?

Ethical issues

Not applicable. 


\section{Competing interests}

The authors declare that they have no competing interests.

\section{Authors' contributions}

GO, DS, SB, and MM contributed to conception and design; acquisition, analysis and interpretation of data; drafting of the manuscript and critical revision of the manuscript for important intellectual content.

\section{Authors' affiliations}

${ }^{1}$ Department of Public Health, Institute of Tropical Medicine, Antwerp, Belgium. 'Law and Development Research Group, Faculty of Law, University of Antwerp, Antwerp, Belgium. ${ }^{3}$ Department of Sociology, Oxford University, Oxford, UK. ${ }^{4} \mathrm{ECOHOST}$, London School of Hygiene and Tropical Medicine, London, UK. ${ }^{5}$ School of Medicine, Stanford University, Stanford, CA, USA.

\section{References}

1. Soebbing BP, Mason DS. Managing legitimacy and uncertainty in professional team sport: the NBA's draft lottery. Team Performance Management. 2009;15(3/4):141-157.

2. Price J, Soebbing BP, Berri D, Humphreys BR. Tournament incentives, league policy, and NBA team performance revisited. J Sports Econom. 2010;11(2):117-135.

3. Quinn KG. Player drafts in the major North American sports leagues. In: Humphreys B, Howard D, eds. The business of Sport. Westport, CT: Praeger; 2008:191-218.

4. Groothuis PA, Hill JR, Perri TJ. Early entry in the NBA draft the influence of unraveling, human capital, and option value. $J$ Sports Econom. 2007;8(3):223-243.

5. Hoang $\mathrm{H}$, Rascher $\mathrm{D}$. The NBA, exit discrimination, and career earnings. Industrial Relations: A Journal of Economy and Society. 1999;38(1):69-91. doi:10.1111/0019-8676.00110

6. Milanovic B. Global Income Inequality by the Numbers: in History and Now: An Overview. Washington DC: World Bank; 2012.

7. Rawls J, Kelly E. Justice as Fairness: A Restatement. Cambridge, MA: Belknap Press; 2001.

8. Adema W, Ladaique M. How Expensive is the Welfare State?: Gross and Net Indicators in the OECD Social Expenditure Database (SOCX). OECD Social, Employment and Migration Working Papers, No. 92. Paris: OECD; 2009.

9. Ricardo D. The principles of political economy and taxation. 3rd ed. London: Empiricus Books; 2002.
10. Fort R, Quirk J. Cross-subsidization, incentives, and outcomes in professional team sports leagues. J Econ Lit. 1995:1265-1299.

11. Kentikelenis A, King L, McKee M, Stuckler D. The International Monetary Fund and the Ebola outbreak. Lancet Glob Health. 2015;3(2):e69-70. doi:10.1016/S2214-109X(14)70377-8

12. Chang HJ. Kicking Away the Ladder: Development Strategy in Historical Perspective. London: Anthem; 2002.

13. McKee M. Opium, tobacco and alcohol: the evolving legitimacy of international action. Clin Med. 2009;9(4):338-341.

14. Basu S, Stuckler D, McKee M. An alternative mechanism for international health aid: evaluating a Global Social Protection Fund. Health Policy Plan. 2014;29(1):127-136. doi:10.1093/ heapol/czs141

15. Ooms G, Hammonds R, Waris A, Criel B, Van Damme W, Whiteside $A$. Beyond health aid: would an international equalization scheme for universal health coverage serve the international collective interest? Global Health. 2014;10:41. doi:10.1186/1744-8603-10-41

16. World Bank. World Bank's Fund for The Poorest Receives Almost $\$ 50$ Billion in Record Funding. Press release, 15 December. Washington DC: World Bank; 2010.

17. Ooms G, Hill PS, Hammonds R, et al. Applying the principles of AIDS 'exceptionality'to global health: challenges for global health governance. Glob Health Gov. 2010;4(1):1-9.

18. Ooms G, Stuckler D, Basu S, McKee M. Financing the millennium development goals for health and beyond: sustaining the 'Big Push'. Global Health. 2010;6:17. doi:10.1186/1744-8603-6-17

19. Doyle C, Patel P. Civil society organisations and global health initiatives: problems of legitimacy. Soc Sci Med. 2008;66(9):19281938.

20. El Saadawi N. The essential Nawal El Saadawi: A Reader. London: Zed Books; 2010.

21. Kennedy DM. Freedom from fear: The American People in Depression and War, 1929-1945. New York: Oxford University Press; 1999.

22. Zinn H. A people's History of the United States: From 1492 to the Present. 2nd ed. London: Longman; 1996.

23. Ooms G. Shifting paradigms: how the fight for 'universal access to AIDS treatment and prevention' supports achieving 'comprehensive primary health care for all'. Global Health. 2008;4:11. doi:10.1186/1744-8603-4-11 